\title{
ALGUNAS PRECISIONES ADJETIVAS SOBRE EL DERECHO DEL NIÑO A SER OÍDO, A PROPÓSITO DE UN ESTUDIO EMPÍRICO
}

SOME ADJECTIVE PRECISIONS OF THE CHILD'S RIGHT TO BE HEARD, ACCORDING TO AN EMPIRICAL STUDY

\author{
FRANCESCO CARRETTA MUÑOZ* \\ Prof. de Derecho Procesal Civil \\ Pontificia Universidad Católica de Valparaíso \\ Valparaíso - Chile
}

\section{RESUMEN}

Se examina el derecho del niño a ser oído desde una perspectiva procesal en la justicia de familia. En esa área sus vértices y contornos no se encuentran suficientemente delimitados, pese a la importancia del derecho que constituye uno de los principios fundamentales de la Convención de Derechos del Niño vigente hace más de 17 años en el mundo. De acuerdo a lo anterior, este trabajo pretende contribuir al desarrollo teórico y práctico del instituto. Para tal labor también se agrega un breve estudio empírico.

Palabras clave: Procedimiento de familia, derecho del niño a ser oído, formas procesales.

\footnotetext{
ABSTRACT

It examines the right of the child to be heard from a procedural perspective in family justice. In this area, its vertices and contours are not sufficiently

* Doctor en Derecho. Profesor agregado de Derecho Procesal Civil de la Pontificia Universidad Católica de Valparaíso. Dirección postal: Facultad de Derecho, Pontificia Universidad Católica de Valparaíso, Casilla 4055, Valparaíso, Chile. Dirección electrónica: francesco.carretta@pucv.cl. El autor agradece a los jueces de familia que colaboraron en el estudio aplicado.

Artículo recibido para su evaluación el 22 de marzo de 2018 y aprobado para su publicación el 23 de mayo de 2018.
} 
delimited, despite the importance of the law, which is one of the fundamental principles of the Convention on the Rights of the Child in force for more than 17 years in the world. According to the above, this work aims to contribute to the theoretical and practical development of the institute. For this work a brief empirical study is also added.

Keywords: Family procedure, the right of the child to be heard, procedural forms.

\section{INTRODUCCIÓN}

El derecho del niño a ser oído (en adelante, DNO), según lo ha señalado Naciones Unidas en la observación $\mathrm{N}^{\circ} 12$ del Comité de derechos del niño, es uno de los valores fundamentales del sistema de protección a la infancia junto con el derecho a la no discriminación, el derecho a la vida y el interés superior. A pesar de ello, un acotado estudio de campo de carácter cualitativo ${ }^{1}$ reveló que existen ciertas dudas por algunos jueces chilenos sobre los lindes y la operatividad del derecho. No se trató de un estudio estadístico que permita afirmar que la realidad judicial es la señalada por aquellos magistrados que fueron parte de la muestra; pero permite visualizar la existencia de incertezas en la ejecución del derecho y cómo éstas pueden desarrollarse en la práctica. Se han sistematizado en 5 puntos que pretenden abarcar los 4 conflictos primordiales detectados en el estudio empírico. Estos son: (i) que no hay una noción clara y uniforme de la estructura del imperativo jurídico que envuelve el DNO y del horizonte normativo donde se encuentra diseminado; (ii) tampoco existe certeza de las formas que deben producirse en la audiencia necesaria para su desarrollo en el proceso; (iii) no hay claridad conceptual ni legal del aspecto binario (edad / madurez) que habilita su ejecución; (iv) se erige a la victimización secundaria como una cortapisa demasiado paternalista y carente de fundamentos reales, que impide el reiterado uso del derecho las veces que es necesario.

\footnotetext{
${ }^{1}$ Se trata de un estudio cualitativo, no estadístico, efectuado el año 2017 a nueve jueces de familia, sobre la base de entrevistas personales semiestructuradas. En ellas se busca pesquisar indicios de las razones por las que los jueces resuelven en base al instituto jurídico objeto de esta investigación. Se pretende contar con un argumento más cercano a la realidad, si bien esta es una obra dogmática. Por ello es sólo un punto de apoyo primario. Un insumo palpable. De ninguna manera se refleja en ella un quantum representativo de la realidad judicial chilena.
} 
Dentro de las aristas detectadas se divisó incertidumbre acerca de la naturaleza de la entrevista reservada, pues no se tiene claridad si se trata o no de un trámite esencial en los términos del recurso de casación en la forma. Aquello supera los alcances y extensión de esta investigación, por lo que será tratado en otro trabajo y será mencionado tangencialmente aquí.

\section{CATEGORÍAS JURÍDICAS QUE COMPRENDE}

Son dos las categorías jurídicas que conforman el DNO. La primera cualidad que resulta patente es la homónima. La implicancia de que se establezca así -como un Derecho- conlleva todas las dimensiones que posee la estructura de aquel imperativo. El avance del constitucionalismo reconduce actualmente el concepto desde un conjunto de reglas con fuerza vinculante que emanan desde el poder político, a uno superior que además amalgama los principios y valores que están inmersos en la Constitución. ${ }^{2}$ Particularmente el juez resulta dotado de un poder mayor, pero de una mayor responsabilidad porque debe hacerse cargo no sólo de las normas en concreto, sino que además de los aspectos valorativos que le irradia la impronta supra legal de la directriz. ${ }^{3}$

El DNO se incorporó al ordenamiento jurídico chileno el año 1990 a través de un tratado internacional sobre derechos humanos, la Convención sobre los Derechos del Niño (en adelante CDN). De esta forma su mandato limita el ejercicio de la soberanía nacional de tal manera que los órganos estatales deben sujetar su accionar a ellos. ${ }^{4}$

Se establece como un principio rector en la ley de tribunales de familia. El artículo 16 expresa: "El interés superior del niño, niña o adolescente, y su derecho a ser oído, son principios rectores que el juez de familia debe tener siempre como consideración principal en la resolución del asunto sometido a su conocimiento". La norma transcrita anuncia una paridad en cuanto la importancia de ambas directrices mencionadas en ella, aunque su contenido es distinto. La igualdad se expresa sobre un aspecto que se ha considerado relevante para la construcción que se pretende elaborar en adelante: que el juez de familia no puede en ningún caso pasar por alto la posibilidad de entrevistar a un niño, como tampoco puede dejar

\footnotetext{
2 AtiEnZA, Manuel, Podemos hacer más, otra forma de pensar el Derecho, Editorial Pasos Perdidos, Madrid, 2013, pp. 33-34.

${ }^{3}$ Atienza, cit. (n.2), pp. 32-40.

4 No obstante que estas afirmaciones pueden ser discutibles para los constitucionalistas. Véase: HENRíqueZ, Miriam, “Jerarquía de los tratados de derecho humanos: análisis jurisprudencial desde el método de casos”, Revista de Estudios Constitucionales, 2008, Vol 6, № 2, pp. 73-119.
} 
de considerar su interés superior ${ }^{5}$ (en adelante NNA). En ese tenor, siempre debe dejar constancia en toda resolución de que cumplió con dicha exigencia, aun cuando haya decidido no entrevistar al niño por causas justificadas. La complementariedad entre ambas ${ }^{6}$ también se ajusta al hecho que el NNA es considerado no sólo una norma sustantiva, sino que también de procedimiento. ${ }^{7}$ En ésta última dimensión se liga con el DNO en cuanto a que la operatividad de aquel depende en buena medida de la pesquisa -procedimiento- que el ente de tutela haga de las opiniones de un niño. En efecto, la forma preeminente de detectar el provecho para el desarrollo de un ser humano es precisamente consultándole aquello que quiere. Sobre estos puntos no hay divergencias, la problemática se gesta sobre la estructura del imperativo en sí. Ello, porque no hay acuerdo en doctrina, y desde ahí, posiblemente en la judicatura, sobre la manera como un principio jurídico se aplica.

Los principios evocan varios significados que trascienden a diversos alcances jurídicos que los operadores suelen conferirle. ${ }^{8}$ Se encuentran presentes en el derecho internacional ${ }^{9}$ y todos los sistemas jurídicos occidentales. ${ }^{10}$ En dichos sistemas se ubican predominantemente en las leyes y códigos. ${ }^{11}$ No obstante, cualquiera sea su fuente, su formulación es

\footnotetext{
${ }^{5}$ Véase: RAVETLlat, Isaac; PinOchet, Ruperto, "El interés superior del niño en el marco de la convención internacional sobre los derechos del niño y su configuración en el derecho civil chileno”, Revista Chilena de Derecho, 2015, Vol. 42, №3, pp. 903-934.

${ }^{6}$ NACIONES UniDAS, "Observación General No 12, el derecho del niño a ser escuchado", 2009, disponible en línea: http://www.acnur.org/t3/fileadmin/Documentos/BDL/2011/7532.pdf?view=1, 21 de agosto de 2017.

${ }^{7}$ NACIONES UnIDAs, “Observación General No 13, sobre el derecho del niño a que su interés superior sea una consideración primordial”, 2001, disponible en línea: http://www.acnur.org/t3/fileadmin/Documentos/BDL/2001/1451.pdf, 21 de agosto de 2017, p. 3.

${ }^{8}$ Lo que suele predicarse de los principios va desde valores culturales, ratio de brocardos, alusiones a categorías lógicas, enunciados de valores normativos, hasta una inducción sacada de un conjunto de normas.

${ }^{9}$ Draetta, Ugo, Principi di diritto delle organizzazioni internazionali, Giuffrè Editore, Milano, 2012, pp. 154-155.

${ }^{10}$ En el derecho anglosajón se asocian a la discrecionalidad del juez, el valor del precedente y las reglas del razonamiento jurídico. MALLESON, Richard; Moules, Kate, The Legal System, Oxford University Press, Reino Unido, 2010, pp. 28-29; CROss, Rupert; HARRIS, James, Precedent in english law, Clarendon Oxford Press, Reino Unido, 1991, pp. 11-12. De alguna manera también se pueden considerar como los estándares sociales y morales a los que debe estar sujeto el Rule of Law. DonATI, Alberto, Rule of law, Comon law, lineamenti, Giuffrè Editore, Milano, 2010, pp. 18-20; COGLIANDRo, Giovanni, Rule of law, la possibilità del contenuto morale del diritto, Giuffrè Editore, Milano, 2012, pp. 143-160. En el sistema norteamericano y anglosajón, cuyo contenido se entiende amplio, pueden entenderse también como los principios de la interpretación de los estatutos, teniendo en cuenta las características de dicho sistema: "canons of construction" o "principles of statutory interpretation". POSNER, Richard, Reflections on judging, Harvard University Press, Cambridge, 2013, pp. 4-6.

${ }^{11}$ ALPA, Guido, I principi generali, Giuffrè Editore, Milano, 2006, p. 6.
} 
confusa. ${ }^{12}$ Se alude a ellos como sinónimos de normas, directrices morales o reglas. Se tornan en generalizaciones que los extienden hasta la vaguedad. ${ }^{13}$ Cuando se trata de principios implícitos, es difícil concretizarlos ${ }^{14}$ y dotarlos de una operatividad concreta. ${ }^{15}$

A partir de la multiplicidad incoherente de información que el juez alberga, éste debe ser consciente que su labor de interpretación/aplicación resultará especialmente compleja. ${ }^{16}$ Sin embargo, puede haber acuerdo en dos alcances mínimos. Primero, que la directriz debe usarse como un canon hermenéutico de los demás derechos que en la Convención y aquellos que en el orden nacional estén conectados a él. ${ }^{17}$ En segundo lugar, ha de entenderse que la norma está indicándole al juez de familia que en toda resolución que tome que pueda afectar los intereses de un infante, debe tener presente la posibilidad de oírlo. Asimismo, deberá consignar los motivos por los que consideró contraproducente o innecesario hacerlo.

\section{ENTRAMADO NORMATIVO}

El marco referencial de todas las leyes que contemplan el DNO lo constituye la Convención de Derechos del Niño (en adelante CDN), específicamente lo que señala el artículo $12 .{ }^{18}$ "Los Estados Partes garan-

\footnotetext{
12 Schauer, Frederich, Playing by the rules, Oxford Clarendon Law Series, Reino Unido, 1991, pp. 19-24.

${ }^{13}$ Aunque hay que hacer algunas precisiones, según Luzzati debemos distinguir la vaguedad de la generalidad. La primera, se refiere a la incerteza de los vocablos, que cae dentro del ámbito de la lingüística, no es por tanto una cuestión de falta de información de los términos. La generalidad en cambio sí posee una certeza, pero que es inútil. Ello por cuanto si bien puede ser verdadera en su aserción, lo será sin contener elementos que detallen su contenido, es de esta manera en algún punto banal. LuZzAtı, Claudio, Principi e principi. la genericità nel diritto, Giappichelli Editore, Torino, 2012, pp. 4-5.

${ }^{14}$ Guastini distingue cuatro (4) desacuerdos existentes en materia de principios: (i) que son aquellas normas consideradas como fundamentales que son dotadas de una importancia especial desde el punto de vista axiológico, (II) si del ordenamiento existen principios implícitos, (III) sobre el modo apropiado de concretizar un principio, y (IV) sobre la forma de ponderar dos principios en conflicto. GuAstini, Riccardo, Distinguendo ancora, Marcial Pons, Madrid, 2013, pp. 34-36.

${ }^{15}$ La relación entre principios y valores también es cercana. BELADIEZ, Margarita, Los principios jurídicos, Thomson Reuters, Navarra, 2010, pp. 192-201. Se identifican con aquellos paradigmas ubicuos que se estiman como correctos en una sociedad. Como una exigencia de la justicia, la equidad o alguna otra dimensión de la moralidad. DwORKIN, Ronald, Taking Rights Seriously, Bloombsbury, London, 2013, p. 46. En síntesis, frente a todas las dificultades anotadas, se puede apreciar que "los principios generan simultáneamente orden y desorden”. Cuestión que en todo caso no es un reclamo actual. EsSER, Josef, Principio y norma en la elaboración jurisprudencial del derecho privado, Bosch, Barcelona, 1961, pp. 3-10.

16 "Pocos principios en las manos de quienes saben usarlos convenientemente, son capaces de alterar el sistema y, al mismo tiempo, de infundirle nueva sabia.” LuZZATI, cit. (n. 13), p. 17.

${ }^{17}$ NACIONES UNIDAS, cit. (n. 6), p. 5.

18 Ídem.
} 
tizarán al niño que esté en condiciones de formarse un juicio propio el derecho de expresar su opinión libremente en todos los asuntos que afectan al niño, teniéndose debidamente en cuenta las opiniones del niño, en función de la edad y madurez del niño. Con tal fin, se dará en particular al niño oportunidad de ser escuchado en todo procedimiento judicial o administrativo que afecte al niño, ya sea directamente o por medio de un representante o de un órgano apropiado, en consonancia con las normas de procedimiento de la ley nacional”.

Se observa que, como una forma de asegurar el derecho, ${ }^{19}$ debe dársele la oportunidad de ser escuchado en todo procedimiento, directamente o por medio de un representante. ${ }^{20}$ En su expresión final, la CDN busca encuadrar todo lo expuesto en la ley procedimental nacional donde se inserte. Con ello la norma no se autorregula, sino que descansa en el rito que cada ordenamiento jurídico tenga previsto para estos efectos. En el caso chileno principalmente en la Ley de Tribunales de Familia $\mathrm{N}^{\circ}$ 19.968 del año 2004 (en adelante LTF). Desde allí se vierte en otras cuatro leyes: la ley de matrimonio civil, la ley sobre adopción, la ley que autoriza el cambio de nombres y apellidos y el Código Civil. ${ }^{21}$

En el artículo 16 de la LTF se anuncia como un principio rector que el juez debe tener como consideración principal para resolver un asunto. La complejidad de que sea descrita como una directriz jurídica ya fue dicha en el párrafo precedente. ${ }^{22}$ Posteriormente, el artículo 69 de la misma ley precisa que en las causas sobre medidas de protección se faculta al juez a escuchar a los niños, y se remite a la CDN, en tanto deberá

\footnotetext{
${ }^{19}$ La observación general número 12 del comité de derechos del niño de Naciones Unidas dota su enunciado de lineamientos más operativos. Tales como que existan garantías por parte de los Estados para la práctica de la diligencia. Naciones Unidas, cit. (n. 6), pp. 9-11.

${ }^{20}$ En la Comunidad Europea también rige el Convenio Europeo sobre el Ejercicio de los Derechos de los Niños, hecho en Estrasburgo el 25 de enero de 1996. La importancia de este instrumento radica que a partir de él se habla del niño como un sujeto procesal y más que ello, dado lo detallada que resultan sus normas, en conferirle una acabada operatividad a sus derechos en la tramitación de un procedimiento, a tal punto que puede estimarse como una parte, en sentido adjetivo. MAGNO, Giuseppe, Il minore come soggetto processuale, commento alla convenzione europea sull'esercizio dei diritti dei fanciulli, Giuffrè Editore, Milano, 2001, p. 4.

${ }^{21}$ Artículos 225-2 f, 227, 229 y 242 del Código Civil. Estas se refieren a los derechos y obligaciones entre padres e hijos.

${ }^{22}$ Las complicaciones que se acostumbra a citar por la doctrina son básicamente tres. Primero, que la formulación de un principio jurídico suele ser ambigua, hay un notable problema terminológico. Por ejemplo, se alude a ellos como sinónimos de normas, directrices morales o reglas. Luego, son imprecisos, es decir, no hay certeza sobre su contenido. En este rumbo, se suele mencionar que son demasiado generales. No hay claridad ni acuerdo sobre cuáles son y cuáles son sus alcances. En tercer lugar, su falta de contenido tangible, por una parte, hace imprecisa su utilidad práctica, y por la otra, los conecta con facilidad al sentido común del sujeto. SCHAUER, cit. (n. 12), pp. 19-24; LUZZATI, cit. (n. 13), pp. 4-5; GUASTINI, cit. (n. 14), pp. 34 -36.
} 
valorarse por el sentenciador la "edad y madurez" para que pueda ser escuchado. Las complejidades de aquello serán examinadas más abajo. Lo que sí es claro, es que al magistrado el ordenamiento le está confiriendo la posibilidad de elegir entrevistar a un niño cuando, de acuerdo con su interés superior, lo encuentre pertinente.

Como contrapartida, siguiendo en la LTF, se consagra el derecho para los niños (art. 79), al que subyace la obligación para el juez, de escucharlo siempre que él lo requiera. En consonancia con la Convención ${ }^{23}$ que no le pone trabas al imperativo y lo plantea en términos amplios. En ese orden de ideas, el niño puede manifestar lo que le sea conveniente, desde antes del proceso hasta incluso después de su final. Recordando que la legislación chilena contiene una amplia tutela cautelar ${ }^{24}$ para la protección de los derechos de la infancia. ${ }^{25}$

Lo dicho hasta aquí se relaciona con el recurso de casación en la forma. Ello, porque la Corte Suprema confunde la esencialidad del acto procesal donde se gesta el imperativo, con la esencialidad intrínseca del derecho. En base a esto, ha procedido a anular sentencias donde el juez no ha citado a un infante para la audiencia confidencial. ${ }^{26} \mathrm{~A}$ pesar de que, como se ha intentado clarificar del análisis de las normas antes consignadas, no es para el juez una obligación, sino una facultad llamar al niño a estrados. Este precedente encuentra cabida en otros fallos de Cortes

\footnotetext{
${ }^{23}$ Artículo 12 de la Convención: “1. Los Estados partes garantizarán al niño que esté en condiciones de formarse un juicio propio del derecho a expresar su opinión libremente en todos los asuntos que afecten al niño, teniéndose debidamente en cuenta las opiniones del niño, en función de la edad y madurez del niño. / 2. Con tal fin, se dará en particular al niño la oportunidad de ser escuchado en todo procedimiento judicial o administrativo que afecte al niño, ya sea directamente o por medio de un representante o de un órgano apropiado, en consonancia con las normas de procedimientos de la ley nacional".

${ }^{24}$ Véase el artículo 22 de la Ley Nº 19.968, 2004.

${ }^{25}$ Sucedió en el tribunal de familia de Valparaíso que dos hermanos de 8 y 12 años concurrieron personalmente a hablar con un juez por la violencia intrafamiliar que se suscitaba entre sus padres. Luego de ser oídos y quedando en evidencia la gravedad de la acusación, aquello motivó la apertura inmediata de un expediente de protección y violencia intrafamiliar. Se citó a los padres a una audiencia preliminar inmediata para la imposición de medidas cautelares, las que, atendido el mérito de los antecedentes fueron adoptadas en beneficio de los niños y la madre.

${ }^{26}$ En el siguiente tenor: "que el deber de otorgar a éste la posibilidad de ser oído en la sustanciación de un proceso en que se pretende determinar su identidad, constituye un trámite esencial del procedimiento cuya omisión debió corregir la Corte de Apelaciones de Santiago, de modo que, al no hacerlo se ha configurado la causal de nulidad formal prevista por el artículo $768 \mathrm{~N}^{\circ} 9$ del Código de Procedimiento Civil, en relación con el artículo 800 del mismo cuerpo de normas, texto que, al designar los trámites o diligencias esenciales en segunda instancia, al igual que lo hace el artículo 795 en relación a la primera instancia, utiliza la expresión: "En general" lo que permite entender que la enumeración que en tales textos se contiene, no es taxativa”. Corte Suprema, 18 de agosto de 2015. En el mismo sentido señalando expresamente la sentencia antes transcrita: Corte de Apelaciones de Valdivia, 17 de octubre de 2016, Rol N 207-2016.
} 
de Apelaciones que se pronuncian en similar sentido. ${ }^{27}$ Como se anunció en la introducción, el examen de este punto dada su extensión no puede ser tratado aquí. Sólo se puede mencionar que varios de los jueces consultados no están de acuerdo con la postura del máximo tribunal. Precisamente por los términos facultativos que está tratada la gestión en todas las leyes donde se vierte el asunto.

"La ley no lo establece como trámite esencial. Es de la esencia del derecho. No es un trámite esencial en la ley.” (Juez \# 5).

“Es importante oírlo, pero esto no debe ser genérico.” (Juez \#6).

"Yo estimo que la ley no establece la obligatoriedad, pero si legalmente lo fuera, no estaría de acuerdo”. (Juez \#4).

Además, aunque es un tema muy discutido atendidas las complejidades que son propias al recurso en examen, ${ }^{28}$ porque con dicha actuación la Corte Suprema excede las atribuciones que le son propias. Ello, porque entra en el conocimiento de cuestiones de hecho que únicamente pueden ser valoradas por los jueces de fondo. Teniendo

27 “Que, el derecho de los niños a ser oídos, que la ley chilena ha catalogado también de primordial, al igual que su interés superior, es otro tema en el cual el Juez tiene una obligación, por mandato del artículo 16 de la Ley 19.698”. Corte de Apelaciones de Punta Arenas, Rol N 47-2011, 7 de julio de 2011, disponible en www.pjud.cl.

"Que en esta causa, dar cumplimiento a tal normativa era especialmente relevante, si se considera que se trataba de disponer la forma cómo debía generarse un régimen comunicacional con un padre ausente por muchos años, todo lo cual provoca en el menor un importante grado de ansiedad, según se deja constancia en uno los informes periciales que la sentenciadora tuvo como elementos de prueba. Escuchar al menor en una materia que es de su directa y total incumbencia, era también posible si se considera que la pericia psicológica da cuenta que tiene un desarrollo físico y maduracional [sic.] propio del ciclo vital en que se encuentra, su desarrollo de lenguaje es apropiado y tiene la capacidad de comprender y expresar ideas de forma clara y fluida. Se daban así las condiciones necesarias para cumplir con tal esencial diligencia, cuyo resultado es determinante al momento de decidir si el derecho que el padre quiere ejercitar debe prevaler sobre el interés superior del menor, que según el artículo $3^{\circ}$ de la Convención ya citada, debe tenerse en cuenta como una consideración primordial. Al no haberse procedido de la manera dicha, se ha faltado a una diligencia, cuyo carácter esencial es incuestionable, siendo la única forma de reparar tal omisión la anulación de la sentencia y del juicio que le sirve de antecedente, por lo que el recurso de casación, sobre la base de esta causal, será acogido”. Corte de Apelaciones de San Miguel, 7 de diciembre de 2011, Rol N 773-2011. En un sentido similar: Corte de Apelaciones de Valdivia, 14 de mayo de 2009, Rol N ${ }^{\circ}$ 103-2009; Corte de Apelaciones de Valparaíso, 18 de julio de 2012, Rol N 274-2012; Corte de Apelaciones de Santiago, 22 de noviembre de 2016, Rol N²215-2016; Corte de Apelaciones de Santiago, 11 de abril de 2016, Rol № 318-2016; Corte de Apelaciones de Santiago, 1 de julio de 2016, Rol N 1264-2016.

${ }^{28}$ ATRIA, Fernando, "La casación como problema”, Revista de Derecho Universidad Adolfo Ibáñez, 2004, Vol. 2, pp. 249 -351. 
también en cuenta que hay discusión por la doctrina sobre los aspectos que pueden ser revisados por las Cortes superiores mediante dicha impugnación. ${ }^{29}$

Continuando con la LTF, está consagrado como uno de los principios de la mediación, en términos singulares. Sólo se citará al niño si su presencia es "estrictamente indispensable para el desarrollo de la mediación”. ${ }^{30}$ Probablemente los legisladores tomaron en cuenta dicha precaución teniendo en consideración que la mediación, aun cuando en muchos casos es obligatoria, no constituye una instancia jurisdiccional.

La Ley de Matrimonio Civil, ${ }^{31}$ en las disposiciones referidas a los juicios de separación, nulidad y divorcio transita por un camino similar a la LTF. En ella especifica que el juez oirá a quién esté en "condiciones de formarse un juicio propio" y repite que aquello debe ser analizado en función de su "edad y madurez".

La Ley de Adopción, cuando se trata de la posibilidad de adoptar o declarar susceptible de adopción a un menor adulto, ${ }^{32}$ establece en su artículo $3^{\circ}$ que el juez, previo a adoptar una decisión sobre el particular, debe pedirle su consentimiento. Este caso es diferente a los ya citados, porque el juez no le consultará otros aspectos de su vida que no sea aquel que señala la norma. La falta de sintonía de esta ley con las examinadas precedentemente es precisamente porque es previo a la incorporación de la Convención en el ordenamiento jurídico chileno.

En el mismo sentido se halla la Ley $\mathrm{N}^{\circ} 17.344$ de $1970 .{ }^{33}$ El inciso final de su artículo primero deja en evidencia su desactualización cuando habla de "menores" que no cuentan con representantes legales o que éstos, si los tuviesen, se nieguen a autorizar el cambio de nombre que solicitó alguno de sus consanguíneos. En ese caso el juez resuelve con audiencia del "menor" y escuchando al "Defensor de menores" o de oficio. De todas maneras, el número de causas de adopción y cambio de nombre en un tribunal de familia son muy inferiores, comparativamente a

\footnotetext{
${ }^{29}$ TARUfFO, Michelle, El vértice ambiguo, Editorial Palestra, Lima, 2005, pp. 222-225; NiEVA, Jordi, El recurso de casación, Legal Publishing, Santiago, 2010, pp. 47-52; TAVOLARI, Raúl, El recurso de casación y queja, Editorial Cono Sur, Santiago, 1996, pp. 1-238.

${ }^{30}$ Artículo 105 e), Ley No 19.968, de 2004.

${ }^{31}$ Artículo 85, Ley N 19.947, de 2004.

${ }^{32}$ Incluso según la opinión de una autora, la obligatoriedad que impone la norma puede trasladarse a los asuntos de filiación, cuando lo que se afecta en un adolescente es su derecho a la identidad y estado civil, tratándose de acciones de impugnación. GREEVEN, Nel, Filiación. Derechos humanos fundamentales y problemas de su actual normativa, Librotecnia, Santiago, 2017, pp. 569-576.

${ }^{33}$ Ley $\mathrm{N}^{\circ} 17.344$ de 1970, sobre Cambio de Nombres y Apellidos.
} 
las otras materias que quedan comprendidas en la competencia de estos tribunales de acuerdo con el artículo 8 de la Ley 19.968. ${ }^{34}$

\section{DESARROLLO DE LAS FORMAS}

Como señalan algunos autores, el ordenamiento jurídico confiere al niño la posibilidad de participar en la construcción del caso. ${ }^{35} \mathrm{El}$ niño y la autoridad encargada de resolver el problema que le aqueja asumen un rol dialéctico ${ }^{36}$ para el restablecimiento de los derechos transgredidos. ${ }^{37}$ En esa confluencia, el derecho destila a través del procedimiento por medio de una diligencia, llamada comúnmente audiencia confidencial. También puede fluir y gestarse en otras formas y modelos de participación, ${ }^{38}$ como la que se puede producir en sede administrativa o policial, o con un carácter meramente colaborativo o participativo. Es importante destacar que el niño no puede ser constreñido a dar su opinión cuando es citado por el juez, aun en aquellas normas donde su declaración es un requisito sine qua non de una resolución que afecta directamente sus intereses. Es decir, el niño puede elegir no ser oído si así lo quiere, sin esgrimir razones para tal elección.

Es interesante notar que existe una disposición que genéricamente describe el lugar donde la diligencia debe efectuarse. El artículo 69 de la LTF dice que la audiencia debe realizarse en "un ambiente adecuado y cautelando su salud física y psíquica”. Una singularidad de aquella norma, a diferencia de las otras que serán expuestas en el próximo capítulo, es que no tiene como referencia a la CDN. El artículo 12 de dicha convención internacional no establece ninguna exigencia sobre la estructura y

\footnotetext{
${ }^{34}$ Por ejemplo, el año 2013 se tramitaron en Chile 2.027 causas por adopción, 70.086 por medidas de protección y 84.559 por violencia intrafamiliar. MinisTerio DE JUSTICIA (CHILE), “Anuario estadístico sobre la justicia de familia”, 2013, recurso electrónico disponible en línea: http://historico.minjusticia.gob.cl/media/2015/04/Anuario-Estadistico-2013-_-Justicia-de-Familia2013.pdf, 21 de agosto de 2017.

${ }^{35}$ Couso, Jaime, "El niño como sujeto de derechos y la nueva Justicia de Familia. Interés Superior del Niño. Autonomía progresiva y derecho a ser oído", documento disponible en línea: http://www.unicef.cl/web/wp-content/uploads/doc_wp/revista\%20derechos\%203_4.pdf, 16 de agosto de 2017, p. 154.

${ }^{36}$ LATHROP, Fabiola, "El derecho del niño a ser oído en el nuevo derecho de familia", Tesis de Grado en Derecho, Universidad de Chile, Santiago, 2002, no publicada, p. 65.

${ }^{37}$ VARGAS, Macarena; Correa, Paula, "La voz de los niños en la justicia de familia en chile", Revista Ius et Praxis, 2011, Vol. 17, № 1, p. 187.

${ }^{38}$ PARKES, Aisling, Children and international human rights law, the right of the child to be heard, Routledge, New York, 2013, pp. 15-16.
} 
localización del trámite. $^{39}$ Presumiblemente, porque de instarse, constituiría la imposición de barreras (adecuaciones presupuestarias), para el expedito ejercicio del derecho, que muchos países derechamente no asumirían y demorarían un tiempo en implementar. El Estado chileno, en cumplimiento del mandato legal, ha ido más allá. En algunos tribunales del país se han habilitado salas especiales denominadas "Gesell” que cumplen con altos estándares para procurar garantizar un ambiente propicio y confidencial para un niño. ${ }^{40}$ Esto se ha regulado detalladamente en el auto acordado 273-2014 que dictó la Corte Suprema para "la implementación y uso de un espacio adecuado para el ejercicio del derecho a ser oídos de niños, niñas y adolescentes en tribunales con competencia de familia”.

Sin embargo, hay muchos aspectos y tramites a propósito de la gestión en comento que se han ido desarrollando por la judicatura en los hechos, sin mayor control que el status quo que se cierne sobre ellos. Sobre estos hay doctrina que justificadamente ejerce algunos cuestionamientos. Uno de ellos es la afectación al derecho de defensa que provoca la exclusión de los abogados de las partes de la práctica de la diligencia, ya que éstos no pueden observar ni escuchar su contenido. ${ }^{41} \mathrm{~A}$ lo que se une el hecho que en las sentencias los jueces no consignan los dichos de los niños, cuestión que perjudica la posibilidad de recurrir adecuadamente de las mismas. $^{42}$

Particularmente difícil resulta determinar si se trata de una prueba, un indicio u otra cosa, cuestión que merece una extensa pesquisa. Por lo pronto, únicamente se puede decir que no posee los mismos cánones que tradicionalmente se les atribuyen a las pruebas judiciales. No se incorpora como tal, no hay sobre ella contra examen, y principalmente no es develada a las partes como para que puedan ejercer sus derechos de impugnación o puedan observarla, previo a la sentencia.

Su contenido comprende no sólo el habla, asimismo el lenguaje no verbal que se gesta desde la infancia temprana. Hay estudios que le atribuyen significado a la gesticulación deíctica de un lactante, entre 8 y 12 meses de edad. Desde ahí y hasta los 15 meses se desarrollan gestos

\footnotetext{
39 Esta afirmación es sin perjuicio de las recomendaciones sobre espacio que ha señalado la observación general $\mathrm{N}^{\circ} 12$. Naciones Unidas, cit. (n. 6), p. 12.

${ }^{40}$ La reserva de la audiencia tampoco es imprescindible, ya que no está exigida en la Convención, ni tampoco en el ordenamiento interno. Sin embargo, como lo ha dicho el Comité de los derechos del niño, si bien la audiencia puede ser pública, es preferible que se haga en condiciones de confidencialidad. Naciones Unidas, cit. (n. 6), p. 14.

${ }^{41}$ FUENTES, Claudio; GARCÍA, Ramón, “Entre la opacidad y la reflexión: a propósito de la práctica de la audiencia reservada ante los tribunales de familia”, Revista de Derecho de Familia, 2015, Vol. 3, No 7, pp. 55-82.

${ }^{42}$ Fuentes y GarCÍA, cit. (n. 41), p. 57.
} 
simbólicos que pueden expresar necesidades. ${ }^{43}$ Sobre el particular, resulta interesante la experiencia de una juez de familia de Pudahuel que relata que, antes de dictar sentencia en una causa, visitó a un lactante que se encontraba en un hogar de protección. En ese lugar apreció la evidente carencia de emociones del niño, que reveló su estado de evidente abandono, que a la postre fue uno de los factores determinantes para declararlo susceptible de adopción. No obstante, y por el tenor literal del artículo 12 de la $\mathrm{CDN}$, no es precisamente el caso reseñado la manifestación de un derecho subjetivo por parte de su agente -el niño-, puesto que a tan temprana etapa de desarrollo carece de la suficiencia de juicio que el ordenamiento pide, para que sean tomadas en cuenta sus expresiones de voluntad. Sería una especie de manifestación en abstracto detectada por el juez, pero no reclamada desde el mismo derecho (DNO), sino desde el deber judicial orgánico de tutela que todo juez de familia se compromete a ejercer desde el momento en que asume su cargo y jura guardar la Constitución y las leyes. ${ }^{44}$

\section{EL DIFÍCIL BINOMIO EDAD-MADUREZ, COMO LOS FACTORES NECESARIOS PARA TENER EN CUENTA LAS OPINIONES DEL NIÑO}

\subsection{Problemática}

Es necesario destacar que el artículo 12 de la CDN se refiere a dos cosas. La habilitación para el trámite de audiencia y el valor que el juez le puede dar a la opinión de un niño. En la primera hipótesis parece decir que debe escucharse a todo niño que esté en condiciones de "formarse un juicio propio". Ergo, aquel que no posea "juicio propio" no debería ser oído. En la segunda, el juez tendrá en cuenta su opinión, pero en directa y proporcional relación a su "edad y madurez". Al juzgar por la estructura gramatical del artículo dicha distinción obedece sólo a una sintaxis, que no hace aconsejable repetir dos veces las mismas palabras. Ello, porque dichas calificaciones (edad, madurez y juicio propio) son tomadas en el contexto de la norma como sinónimos. Resultaría contradictorio concluir que un niño puede formarse un juicio propio y luego que no tiene la edad suficiente para opinar, o la madurez. En el fondo, la capacidad de expresar cordura y sensatez no puede permanecer ajena a aquellas dos

\footnotetext{
43 FARKAS, Chamarrita, "Comunicación gestual en la infancia temprana: una revisión de su desarrollo, relación con el lenguaje e implicancias de su intervención”, Revista Psykhe, 2008, Vol. 2, $\mathrm{N}^{\circ} 16$, p. 108.

${ }^{44}$ Artículo 304 del Código Orgánico de Tribunales.
} 
circunstancias. Lo único que podría esgrimirse para establecer una distinción con cierto sentido, es estimar que el estándar para que el niño concurra a prestar declaración es más bajo que aquel que el juez debe tener en cuenta para tomar en consideración sus palabras. Pero ello conlleva la posibilidad de escucharlo inoficiosamente.

Estas dificultades no se quedan en una cuestión meramente terminológica, sino que encuentran un correlato factual. En Chile, como en otras latitudes, ${ }^{45}$ la alternativa de oír a un niño confronta a tres circunstancias: la prudencia del juez, entendida ésta como la templanza de una persona para tomar una elección, dentro de las posibles opciones, y dos coeficientes evolutivos: la edad y madurez. Se comprende que no es tarea fácil para un magistrado asirse de dichos factores, ${ }^{46}$ sobre todo si para su determinación deberá hacer indagaciones que no son propias de la labor habitual de un letrado. Por otra parte, tampoco la legislación chilena establece rangos etarios, ni siquiera referenciales, a partir de los cuales se pueda tener un baremo para orientar o recomendar cuando resulta prudente escuchar a un niño. ${ }^{47}$

No obstante, la pesquisa experimental que se agrega a esta prospección revela que algunos jueces chilenos coinciden en que en ningún caso se puede entrevistar a un niño de un rango menor entre los 3 y 5 años. Sin perjuicio que varios armonizan en que la edad puede ser inferior cuando debe apreciarse el lenguaje corporal. En ese sentido son las siguientes opiniones:

“Un niño debería ser escuchado a través de su percepción física. La planitud emocional es indiciaria de problemas serios en un niño, en cuanto a su abandono" (Juez \#3).

"La expresión corporal también constituye una forma de escuchar al niño” (Juez \#2).

\footnotetext{
${ }^{45}$ El artículo 159 del Código Civil español establece que los niños mayores de 12 años deben ser obligatoriamente escuchados, previo a la decisión sobre su cuidado personal. Los artículos 173.2 sobre acogimiento familiar, 92 sobre custodia; 156 en el ejercicio de la patria potestad; 231y 273, sobre tutela; y 178 sobre adopción del mismo Código. Allí se habla de del "suficiente juicio".

${ }^{46}$ SÁNCHEZ-EzNARRIAGA, Zarraluqui, "El menor en los procesos de familia”, en Alcón Yustas M. F.; Jääskeläinen F. (eds.), Los menores en el proceso judicial, Tecnos, Madrid, 2011, p. 60.

${ }^{47}$ Salvo el caso de la adopción analizado en el acápite anterior que en todo caso no se condice con la doctrina que sobre el particular se desprende de la Convención y las observaciones que se han gestado alrededor de ella, que se puede predicar en el siguiente tenor: no hay ningún límite psicoafectivo, etario, de diagnóstico en el ámbito de la salud, ni relacionado a la naturaleza del asunto que subyace a la problemática que lo afecte, para que el niño pueda ejercer su derecho a ser oído.
} 
"También considero todos los antecedentes indirectos por los que el niño se expresa, como los informes que las redes intermedias o pericias vierten sobre ellos” (Juez \#9).

Es posible que la edad esté asociada a la posibilidad que el niño pueda hablar. Sin embargo, si se tratara sólo de esperar la manifestación de un lenguaje verbal, entonces la cuestión se trasladaría exclusivamente a indagar si el niño sabe o no hacerlo con cierta fluidez. Esto se produce aproximadamente a los cuatro años. ${ }^{48}$ Por ello, la edad se acompaña inseparablemente de la madurez. Nótese que la norma base (artículo $5 \mathrm{CDN}$ ) habla de la evolución de las facultades y las que le siguen no despegan el aspecto binario, significando así que, por sí sola, la edad no es un patrón válido de juzgamiento.

El juez debe apreciar ambas características a la vez, si se toma en cuenta que las normas contienen la conjunción " $y$ ”. En ese sentido, la edad a lo menos es un factor biológicamente objetivo cognoscible por el juez al momento de la interposición de la acción. La madurez, en cambio, entendida como "el buen juicio", o como "la capacidad de un niño para expresar sus opiniones sobre las cuestiones de forma razonable e independiente", ${ }^{49}$ no es palpable con tanta certeza.

Sucede que son muchas las ocasiones en que el juez de familia deberá tomar resoluciones urgentes a favor del NNA, donde deberá pesquisar su opinión y no tendrá más que la presencia del infante. Particularmente en las medidas de protección o cautelares prejudiciales que habitualmente se presentan.

El cálculo de la evolución de la plenitud de un ser humano requiere de algún tipo de apreciación mayor a un solo aspecto. ${ }^{50}$ La progresión comparativa "edad-madurez" no coincide el cien por ciento de las veces. Esto dice relación con otro de los aspectos que está estrechamente vinculado con el DNO, la llamada autonomía progresiva que está expresamente planteada en el mismo artículo 12 y 5 de la CDN. Sobre dichas normas se señala: “A medida que el niño madura, sus opiniones deberán tener cada vez

\footnotetext{
${ }^{48}$ Olea, R.; NeIRA, E.; SANHUEZA, F., “Anomalías en el desarrollo del lenguaje”, Revista Chilena de Pediatría, 1958, Vol. 29, N², p. 58.

${ }^{49}$ NACIONES UNIDAS, cit. (n. 6), p. 11.

${ }^{50}$ En este punto es interesante destacar el artículo 7 del proyecto de ley de sistemas de garantías de la niñez, a propósito de la autonomía progresiva, utiliza la edad y madurez como uno de los requisitos para el ejercicio que un niño pueda hacer de sus derechos. Pero dicha norma indaga en aspectos subjetivos con mayor rigor al establecer que todos deben ser apreciados en función de la directa relación con la "evolución de sus facultades", y aunque la norma no lo dice, ha de suponerse que se refiere al desarrollo temporal de un sujeto, en todas las facetas de su vida.
} 
más peso en la evaluación de su interés superior”, ${ }^{1}$ lo que resulta de alguna manera obvio.

Con todo, el lapso temporal -a medida que- que sugiere la norma, es el quid cuya apreciación por un letrado está lejos de ser elemental. Pero, como ya se expresó, si el juez no posee antecedentes más concretos, sobre todo en las instancias iniciales de un proceso, ¿a qué recurre? Posiblemente a la conjetura que, a mayor edad, un ser humano es gradualmente más maduro, pero esto significa que en el fondo se está decidiendo sólo en base a la edad.

De acuerdo con todas las observaciones planteadas, nace la pregunta: ¿Puede el juez apreciar de antemano factiblemente todas las aristas que contiene el factor madurez, para decidir escuchar al niño? En principio sí, si cuenta con todos los antecedentes referidos exclusivamente a la personalidad del niño para determinarlo. Generalmente no, si en la gran cantidad de los casos que se le presentan a diario, sobre todo urgentes, no tendrá a la vista aquellos documentos o pericias.

\subsection{La complejidad del caso como un parámetro objetivo}

Frente a los inconvenientes planteados en el acápite anterior, las opiniones recogidas en la muestra otorgan una alternativa singular. Algunos de los jueces entrevistados, en no pocas ocasiones prescinden del binomio y han expresado la necesidad de escuchar al niño exclusivamente en casos que habitualmente se consideran difíciles. Estos son aquellos donde su opinión resultará del todo relevante para adquirir convicción sobre la mejor tutela de los derechos.

“Es indispensable en adopción, susceptibilidad y protección (...) En alimentos y divorcio no es indispensable escucharlo, separación judicial, declaración de bien familiar, etc. En estos casos ni si quiera los cito (...)” (Juez \#9).

“considero necesario escucharlos en Protección, susceptibilidad, cuidado personal y relación directa y regular, prescindo en alimentos, las voluntarias y divorcio” (Juez \#1).

${ }^{51}$ En términos simples la autonomía progresiva supone que "a medida que el niño madura, sus opiniones deberán tener cada vez más peso en la evaluación de su interés superior.” Naciones Unidas, cit. (n. 7), p.12. 
La "complejidad del caso" unida a la edad son dos antecedentes más concretos a la hora de apreciar rápidamente la necesidad de que el DNO sea ejercido. En la judicatura de familia resulta conocido definir tipologías de casos, entre más o menos complejos. Aquello está expresamente establecido en el acta 71-2016 como una obligación de cada tribunal en la elaboración de su plan anual de trabajo. Actualmente, en un buen número de expedientes ${ }^{52}$ existe un acceso rápido a la información, debido a que la interconexión computacional con otros procesos y redes intermedias crece y se perfecciona constantemente. Teniendo en cuenta también que los casos complicados generalmente vienen acompañados de antecedentes anteriores sobre el mismo niño o las familias en que está inserto, con los que se puede contar de inmediato según lo permite el sistema SITFA. ${ }^{53}$

La complejidad del caso dice relación con aspectos cuantitativos y atributivos.

Los primeros, dicen relación con la mayor o menor cantidad de material probatorio que las partes y el tribunal incorporen al juicio, lo que sucederá desde la interposición de la acción vía demanda, requerimiento o denuncia, hasta la audiencia preparatoria; la cantidad y complejidad de los peritajes incluidos en la causa; el número de sujetos involucrados, puesto que en muchos casos está directamente involucrada a lo menos la familia nuclear del sujeto de protección.

Los segundos, es decir, los cualitativos, se refieren a la ponderación de si lo que se decidirá implicará la separación del niño de su grupo familiar o referentes afectivos. Si hay una lesión a su integridad física o síquica, etc. En general, todas aquellas causas que signifiquen una decisión que vaya a afectar sustancialmente el NNA. Por el contrario, existen casos en que la precisión y suficiencia de los antecedentes concomitantes permiten al juez llegar a una decisión que no le genera dudas de que, para arribar a ella, no era necesario escuchar al niño. Tales pueden ser aquellos donde se discute una pensión de alimentos; donde se deba designar un curador de bienes, se discuta sobre un bien familiar, se trate de un divorcio unilateral allanado o de común acuerdo donde previamente se hayan tomado en cuenta sus derechos, etc.

La optimización de los casos donde el niño concurra a estrados -lo que quiere decir que no será llamado en todos ellos-, al inicio del pleito, o durante el iter, evita que sea citado inútilmente. Eso sí, tomando en cuenta

\footnotetext{
${ }^{52}$ El parámetro que se está describiendo no sirve en todas las causas, ya que, en las etapas tempranas de un proceso, el juez no goza de un copioso material de análisis, salvo el certificado de filiación que sirve para la determinación de la edad.

${ }^{53}$ Sistema informático de Tribunales de Familia.
} 
el argumento que con ubicuidad se expone en este estudio: que el juez debe en todos los casos expresar la razón, para escucharlo o no.

\section{LA VICTIMIZACIÓN SECUNDARIA}

\subsection{Explicación general del fenómeno}

Sobre todos los puntos señalados hasta aquí se cierne la sombra de la denominada "victimización secundaria". A grandes rasgos, se entiende por tal el fenómeno que produce un daño en los sentimientos del niño, al tener éste que enfrentarse al sistema de justicia, después del complejo episodio que lo trae a él y que de alguna manera lo hace revivir la vivencia traumática. ${ }^{54}$ Es la secuencia temporal entre el evento que origina el juicio y la ficticia repetición o rememoración de éste, la que le da al suceso el adjetivo de "secundaria". Conforme a ello, se tiene la idea que la mayor cantidad de veces que un niño asista a un tribunal agravará el daño. Pero se percibe como una aprehensión más paternalista que efectiva.

Esto se confronta a la verdadera necesidad que se tiene en determinadas situaciones de escucharlo, más de una vez, con el hecho probable que los jueces que manejan un mismo expediente sean distintos. ${ }^{55}$ Porque puede ocurrir que sea uno el que le da inicio, otro el que está en la audiencia preliminar, otro el que dicte sentencia y uno distinto el que resuelve medidas cautelares, por falta o ausencia del juez radicado. Sobre todo, en tribunales de muchos jueces como Santiago o Concepción. En esas circunstancias puede ocurrir que el juez sentirá, por una parte, que, para tomar una resolución cautelar, interlocutoria o de término debe escuchar al niño, y por la otra, se sienta presionado porque otro juez ya lo hizo.

Y aunque pueda encapsularse electrónicamente la sesión de escucha por medio de una grabación, puede que al juez no le sea aquello satisfactorio. Ello, porque las circunstancias actuales son diversas a las primarias, o porque el juez, escuchando la grabación, no quede satisfecho con los aspectos abordados por su colega. Este tipo de juicios no son como los que se tramitan en sede civil o penal, en que las pretensiones y objeto

\footnotetext{
54 NúÑEZ, D.; Arredondo, V.; CARrasco, C.; Guerra, C., “Significados asociados a la participación en juicios orales en niños y niñas víctimas de delitos sexuales”, Revista Praxis, 2015, vo1. $17, \mathrm{~N}^{\circ} 27$, pp. $61-81$.

${ }^{55}$ Esto es, sin perjuicio de las instrucciones actuales sobre la materia, que permiten que las causas de esa naturaleza se radiquen en un mismo juez. Corte Suprema, Acta $N^{\circ}$ 237-2014, Auto Acordado que regula la implementación de las salas Gesell, http://www.intranet.pjud/base_documental/, 21 de agosto de 2017.
} 
del juicio permanecen inalterables. Hay un ir y venir de factores e incluso personas involucradas durante el transcurso del procedimiento, en constante movimiento de la mano de los poderes oficiosos del juez. ${ }^{56}$

In situ, la asistencia a un tribunal posee efectos desde antes de la concurrencia al mismo. El conflicto que origina un procedimiento se produce la mayoría de las veces en el entorno familiar y permanece mientras no se dicten medidas de protección. El niño, antes de ir, eventualmente sabrá que debe hacerlo y la razón. El día señalado concurrirá con quien lo tenga a su cuidado, probablemente uno de los sujetos involucrados en el daño. ${ }^{57}$ Luego, tomará contacto con los oficiales de justicia quienes le explicarán la práctica de la diligencia. En este nivel no se tiene noción de la forma de trato que se le puede dar, ya que no existen protocolos. Después debe esperar su turno de acuerdo con la agenda, en un lugar poco amigable. Finalmente, rendirá su declaración que versará sobre aquello que lo perturbó, en la que se deben considerar los pormenores vistos en el desarrollo de la audiencia, señalados en el capítulo IV. Pero el quid de este asunto no está en la secuencia de trámites, sino en determinar si esas actuaciones producirán una lesión en el NNA.

\subsection{Sector de estudio}

Es bueno despejar que lo comúnmente se conoce por victimización secundaria, no es un suceso que nace desde la observación del sistema de tutela de la infancia y adolescencia, sino del sistema penal. En esa área está referido específicamente a las figuras delictivas relacionadas a los atentados en la esfera de la sexualidad. ${ }^{58}$ Aquí no se discute tanto el hecho que un individuo afectado por la comisión de un ilícito -el niño-, deba luego concurrir a un tribunal de justicia en una o varias ocasiones. Ese es el entendimiento primario que la mayoría de los jueces entrevistados poseen. Algunos ejemplos de aquello son los que se citan a continuación. Otros se verán infra.

\footnotetext{
${ }^{56}$ Con polémica en la doctrina sobre la forma como esos poderes oficiosos se emplean. FUENTES, Claudio, "Los dilemas del juez de familia”, Revista Chilena de Derecho, 2015, Vol. 42, pp. 935 965.

${ }^{57}$ Suele suceder que en este punto se detecte la manipulación por parte del adulto responsable, de lo que el niño diga, lo que traslada la cuestión a un conflicto anexo: el síndrome de alienación parental. Maida, A.; Herskovic, V.; Prado, B., “Síndrome de alienación parental”, Revista Chilena de Pediatría, 2011, Vol. 82, № 6, pp. 485-492.

${ }^{58}$ Gutiérrez de Pineres Botero, C.; Coronel, E.; PÉrez, A., "Revisión teórica del concepto de victimización secundaria”, Revista Liber, 2009, Vol. 1, N 15, pp. 49-58.
} 
“Cito al niño, solo si es estrictamente necesario. Ello porque citarlo al tribunal puede ser vulneratorio. A fin de evitar victimización secundaria” (Juez \#5).

“Cito al niño solo una vez por la victimización” (Juez \#7).

Es, más que un asunto del "número de veces", la respuesta inadecuada o mala atención que recibe de las instituciones a las que debe concurrir con ocasión del delito que la afecta, entre ellas un tribunal de justicia. Hay investigaciones empíricas ${ }^{59}$ que muestran que el comportamiento de los profesionales encargados de atender a las víctimas no es precisamente el que comúnmente se puede pensar. Existe un extraño efecto sicológico que se produce frente a eventos traumáticos que el ser humano puede sufrir, por el cual aquellos que no lo sufrieron se sienten aliviados, aunque no hayan tenido nada que ver con el episodio. Estos operadores, de acuerdo con el estudio, pueden presentar respuestas inadecuadas o no esperables frente a la víctima, especialmente cuando se estima que no es culpable de lo que le aconteció.

En el sistema criminal, para recabar la declaración del niño intervendrá el Ministerio Público, la institución encargada de hacer la pericia y un tribunal de justicia. En todos ellos tomará contacto con más de una persona para prestar su testimonio. Se une a esto el hecho que no en pocos casos la víctima -el niño- es desplazada o invisibilizada, en favor de las incidencias propias de la persecución penal que dirige todos sus esfuerzos al descubrimiento del delito y la condena en contra del imputado. De la misma forma, resultará vulneradora la duración de los procesos que se une a la angustia por el conocimiento de sus resultados. ${ }^{60}$

Además, cuando se trata del abuso sexual infantil, lo delicado será, aparte de lo mencionado arriba, la difícil pesquisa de este tipo de hechos. ${ }^{61}$ Esta se asienta en el mayor detalle de lo que el niño pueda relatar, pasando por la cantidad de pericias previas a las que son sujetos y el cuestiona-

59 HirschBerger, Gilad, “Terror Management and Attributions of Blame to Innocent Victims: Reconciling Compassionate and Defensive Responses”, Journal of Personality and Social Psychology, 2006, № 9, pp. 832-844.

${ }^{60}$ Pero, esas disquisiciones son del campo de la sicología clínica y solo se citan aquí para demostrar que las propias concepciones sobre el fenómeno descrito muchas veces no calzan con la realidad. También evidencian que quizá sea la hora de que la investigación jurídica se alinee e interactué con otras ciencias, en un sector -el derecho de familia- donde la dogmática no es suficiente para encontrar respuestas a los complejos dilemas del comportamiento humano. Menos causas donde la indagación debe partir primero en el espacio volitivo del comportamiento humano.

${ }^{61}$ NuñEZ, D.; Arredondo, V.; Carrasco, C.; Guerra, C., cit. (n. 54), pp. 61-81. 
miento de la veracidad de la declaración. ${ }^{62}$ También resalta la presión de que sean interrogados por el fiscal y el defensor, aunque esto se haga por intermedio del juez. ${ }^{63}$ Estas vicisitudes de la investigación criminal les produce una comprobada ansiedad. Para remediarla, se proponen por la literatura programas de apoyo. ${ }^{64}$ En ellos se propende a familiarizarlos con el entorno propio de los trámites, gestiones y ambiente de un proceso punitivo, antes de que presente declaración. ${ }^{65}$

En suma, frente a las disfuncionalidades que existen en el trato de los operadores hacia los niños y demás aspectos vistos, lo mejor es, en sede punitiva, no exponerlos a citaciones innecesarias y procurar hacerlo el menor número de veces.

\subsection{Extrapolación infructuosa}

Todo lo expresado hasta ahora no se puede trasladar sin más a la justicia de familia. Los parámetros del juzgamiento penal son muy distintos. La justicia del crimen se valdrá de la declaración del niño para el castigo del culpable. La indagación está dirigida necesariamente a repetir verbalmente la vivencia traumática. En ese orden de ideas, la declaración no se puede considerar como la manifestación libre de su derecho a ser oído. Ello, porque para que la persecución penal tenga mayores probabilidades de éxito, deberá expresar necesariamente las circunstancias del atentado que sufrió. No es así en sede de familia. Las materias por las que es escuchado un niño en audiencia confidencial que se encuentran en el amplio catálogo del artículo 9 de la LTF, no se refieren a la comisión de ilícitos donde el niño es víctima. ${ }^{66}$ En consecuencia, no se divisan muchos puntos de encuentro entre lo que acontece en ambas competencias

\footnotetext{
${ }^{62}$ CAtAnesi, R.; Amerio, L., "L'attendibilità del minore”, en Bandini T.; Gualco B. (eds.), Infanzia e abuso sessuale, Giuffrè, Milano, 2000, pp. 299 - 320.

${ }^{63}$ Sobre el particular hay norma expresa en el artículo 310 del Código Procesal Penal chileno que obliga a los intervinientes a efectuar las preguntas pertinentes por intermedio del juez presidente del tribunal.

${ }^{64}$ Referido también a la justicia transicional: MicHELS, An, "Psychosocial Support for Children: Protecting the rights of child victims and witnesses in transitional justice processes”, Innocenti Working Paper, 2009, No 14, pp. 1-6.

65 Vio, C.; BARrera, M.; LAZO, B.; Quiroz, P.; TAPIA, F., "Niveles de ansiedad en niños victimizados: aportes de un programa de preparación”, Revista de Psicología, 2011, Vol. 20, № 2, pp. 8-24.

${ }^{66}$ Tangencialmente puede ocurrir que un niño sea escuchado por el abuso sexual que pueda haberle acontecido. Pero en tal caso, el juez es libre para decidir oírlo, ya que lo hará siempre que concurra el binomio edad-madurez que tantas veces se ha citado en este estudio. En función también de su interés superior y siempre que el niño quiera hacerlo.
} 
jurisdiccionales, como para extrapolar lo que sucede desde un área a la otra.

No obstante, como aparece del examen cualitativo, varios jueces de familia entrevistados ven en el fenómeno descrito una traba que los lleva a ser demasiado cautelosos en ejercer su facultad de escuchar al niño. Con mayor rigor, si esto debe ser ejecutado en más de una oportunidad. Frente a la pregunta ¿Qué entiende usted por victimización secundaria?, algunas de las respuestas son las siguientes:

"Es aquella circunstancia que se produce en una víctima cuando tiene que revivir un evento traumático en distintas personas y más de una vez” (Juez \#1).

"La vulneración de indagar una y otra vez en relación con el propio niño, para obtener información” (Juez \# 6).

"Entiendo que cuando sometes al niño al sistema judicial una y otra vez y a las intervenciones terapéuticas” (Juez \# 8).

"Me parce que someter al niño al sistema judicial reiterativamente. Desde el enfoque de derechos y desde el requerimiento del tribunal” (Juez \# 9).

Todos coinciden en que el obstáculo para hacerlo en varias ocasiones es la victimización secundaria, aduciendo sólo al factor cuantitativo que envuelve el escucharlo en múltiples ocasiones. Pareciera que el atentado se produce por la repetición, más allá de las circunstancias específicas que la reiteración conlleva. El problema es que, a diferencia de la justicia penal, no se sabe con exactitud si escuchándolo un mayor número de veces hay una lesión al NNA. En consecuencia, las razones para que no sea escuchado a libre demanda, según lo requiera su interés, se quedan en un campo especulativo peligroso. Ello, porque el hecho de no proceder a la actuación referida todas las veces que sea necesario, para procurar la tutela adecuada de sus derechos, es paradojalmente por sí misma una especie de vulneración.

Pero todo debe ser sometido a una ardua pesquisa, que al igual que en el orden criminal se encamine a desentrañar el perjuicio efectivo que se produce, que extiende el campo de análisis de esta prospección e incluso el área de la investigación jurídica. Lo que se pretende en este ensayo, de acuerdo con el bosquejo previsto en la introducción, es notar que las 
cortapisas que los jueces pueden tener actualmente para no oír a un niño carecen de un fundamento mayor al mero sentido común.

\section{CONCLUSIONES}

El derecho del niño a ser oído envuelve el desarrollo de formas procesales, categorías jurídicas e intrincados aspectos de hecho que este estudio ha pretendido evidenciar preliminarmente.

Es un tema sumamente relevante, no por nada, se encuentra presente desde el año 1990 en la Convención de Derechos del Niño como uno de sus vértices. Desde esa cúspide desciende a varios apartados legislativos que en su mayoría parafrasean lo que sobre él se predica en dicho tratado. El análisis literal de las normas donde se contiene revela contornos abiertos que encuentran un correlato en el breve análisis empírico que se dio a conocer en esta obra. Ello, porque hay dudas en los jueces entrevistados sobre los aspectos jurídicos y prácticos de la directriz. En ese orden de ideas, se ha querido efectuar una ordenación cuyos resultados iniciales permiten esbozar algunas respuestas a las interrogantes planteadas en la introducción, o a lo menos servir de tópico para su elaboración. Además, los patrones similares contenidos en las leyes donde se encuentra permiten cimentar una sistematización básica acerca de sus márgenes.

Es el DNO un principio jurídico que, a parte de los alcances propios que le confiere dicha impronta, presenta dos niveles.

Uno que otorga al magistrado la posibilidad, no la obligación, de escuchar al niño todas las veces que estime necesario hacerlo, a la luz de su interés superior. Alternativa que queda de manifiesto en el hecho que, de acuerdo con la Convención y la ley, deberá valorar primero su edad y madurez para hacerlo. Estos ingredientes de análisis subjetivo reportan cierta dificultad en su apreciación, por lo que puede que con el tiempo se vayan desplazando hacia la complejidad del caso. Esto es a lo que actualmente suelen recurrir algunos magistrados para decidir sobre este punto.

El otro nivel, pertenece al imperativo mirado desde el punto de vista del infante. Éste, en el ámbito del derecho de familia e infancia, no puede ser constreñido a manifestar su parecer. Si decide hacerlo, el lenguaje verbal no es el único que el magistrado deberá tomar en cuenta, también debe considerarse la expresión corporal. Por ello, no puede construirse un baremo que se limite a determinados rangos etarios que establezcan cuándo es preferible llevar a cabo el trámite. 
El estudio experimental revela algunos indicios que permiten pensar que la victimización secundaria se puede estar erigiendo como un obstáculo demasiado grande para el libre ejercicio del derecho. A pesar de que no se tiene constancia de los efectos que produce en un niño el hecho de concurrir a un tribunal de familia en más de una ocasión. Se observó que, en la justicia penal, estudios han precisado consecuencias negativas específicas ocasionadas por la victimización. Pero ellas no se pueden trasladar sin más al área de la justicia de familia que transita por variables diversas. Así, mientras queda bastante por descubrir de este fenómeno, quizá es preferible que los jueces de familia no piensen a priori que citar a un niño en las todas las oportunidades que sean adecuadas será perjudicial para ellos.

Por último, de acuerdo a todos los elementos que se han vertido en este estudio y de cara a la delimitación y mejor entendimiento del instituto se hace necesario ensayar un concepto. Desde un punto de vista procesal, el derecho en referencia es: el imperativo legal que emana del interés superior de los niños, por el que éstos pueden manifestar libremente, de cualquier manera y por cualquier medio sus opiniones en todos los procedimientos administrativos o judiciales en que se decida cualquier aspecto concerniente a sus vidas, sobre las que la autoridad está obligada a tener en cuenta la posibilidad de escucharlos o no, consignando en sus resoluciones siempre los argumentos de aquella consideración.

\section{BIBLIOGRAFÍA CITADA}

\section{Doctrina}

ALPA, Guido, I principi generali, Giuffrè Editore, Milano, 2006.

AtienZA, Manuel, Podemos hacer más, otra forma de pensar el Derecho, Editorial Pasos Perdidos, Madrid, 2013

ATRIA, Fernando, “La casación como problema”, Revista de Derecho Universidad Adolfo Ibáñez, 2004, Vol. I, N² 2.

Beladiez, Margarita, Los principios jurídicos, Thomson Reuters, Navarra, 2010.

CATANESI, R.; AMERIO, L., "L'attendibilità del minore”, en Bandini T.; Gualco B. (eds.), Infanzia e abuso sessuale, Giuffrè, Milano, 2000. 
Cogliandro, Giovanni, Rule of law, la possibilità del contenuto morale del diritto, Giuffrè Editore, Milano, 2010.

Couso, Jaime, "El niño como sujeto de derechos y la nueva Justicia de Familia. Interés Superior del Niño. Autonomía progresiva y derecho a ser oído", disponible en línea: http://www.unicef.cl/web/wpcontent/uploads/doc_wp/revista\%20derechos\%203_4.pdf, 16 de agosto de 2017.

Cross, Rupert; HARRIS, James, Precedent in english law, Clarendon Oxford Press, Reino Unido, 1991.

DonAtı, Alberto, Rule of law, Comon law, lineamenti, Giuffrè Editore, Milano, 2010.

DraETTA, Ugo , Principi di diritto delle organizzazioni internazionali, Giuffrè Editore, Milano, 2012.

DWORKIN, Ronald, Taking Rights Seriously, Bloombsbury, London, 2013.

ESSER, Josef, Principio y norma en la elaboración jurisprudencial del derecho privado, Bosch, Barcelona, 1961.

FARKAS, Chamarrita, "Comunicación gestual en la infancia temprana: una revisión de su desarrollo, relación con el lenguaje e implicancias de su intervención”, Revista Psykhe, 2008, Vol. 2, № 16.

FuENTES, Claudio, "Los dilemas del juez de familia”, Revista Chilena de Derecho, 2015, vol. 42.

FUENTES, Claudio; GARCÍA, Ramón, "Entre la opacidad y la reflexión: a propósito de la práctica de la audiencia reservada ante los tribunales de familia”, Revista de Derecho de Familia, 2015, Vol. 3, № 7.

GREEVEN, Nel, Filiación. Derechos humanos fundamentales $y$ problemas de su actual normativa, Librotecnia, Santiago, 2017.

GuASTINI, Riccardo, Distinguendo ancora, Marcial Pons, Madrid, 2013.

Gutiérrez de Pineres Botero, C.; Coronel, E.; Pérez, A., "Revisión teórica del concepto de victimización secundaria", Revista Liber, 2009, Vol. 1, N 15.

HENRíquez, Miriam, "Jerarquía de los tratados de derecho humanos: análisis jurisprudencial desde el método de casos", Revista de Estudios Constitucionales, 2008, Vol 6, $\mathrm{N}^{\circ} 2$.

HIRSCHBERGER, Gilad, "Terror Management and Attributions of Blame to Innocent Victims: Reconciling Compassionate and Defensive Responses”, Journal of Personality and Social Psychology, 2006, № 9. 
LATHROP, Fabiola, "El derecho del niño a ser oído en el nuevo derecho de familia”, Tesis de Grado en Derecho, Universidad de Chile, Santiago, no publicada, 2002.

LuZZATI, Claudio, Principi e principi. la genericità nel diritto, Giappichelli Editore, Torino, 2012.

MAGNO, Giuseppe, Il minore come soggetto processuale, commento alla convenzione europea sull'esercizio dei diritti dei fanciulli, Giuffrè Editore, Milano, 2001.

Maida, A.; Herskovic, V.; Prado, B., "Síndrome de alienación parental”, Revista Chilena de Pediatría, 2011, Vol. 82, N ${ }^{\circ} 6$.

MALleson, Richard; Moules, Kate, The Legal System, Oxford University Press, Reino Unido, 2010.

Michels, Ann, "Psychosocial Support for Children: Protecting the rights of child victims and witnesses in transitional justice processes", Innocenti Working Paper, 2009, № 14.

MinisTERIO DE JUSTICIA (CHILE): “Anuario estadístico sobre la justicia de familia”, recurso electrónico, 2013, disponible en línea: http://historico.minjusticia.gob.cl/media/2015/04/Anuario-Estadistico-2013_-Justicia-de-Familia-2013.pdf, 21 de agosto de 2017.

NACIONES UNIDAS, "Observación general $\mathrm{n}^{\circ} 12$, el derecho del niño a ser escuchado”, 2011, recurso electrónico disponible en línea: http://www.acnur.org/t3/fileadmin/Documentos/BDL/2011/7532.pdf?view= 1, 21 de agosto de 2017.

NACIONES UNIDAS, "Observación general $\mathrm{N}^{\circ} 13$, sobre el derecho del niño a que su interés superior sea una consideración primordial”, 2001, recurso electrónico disponible en línea: http://www.acnur.org/t3/fileadmin/Documentos/BDL/2001/1451.pdf, 21 de agosto de 2017.

NieVA, Jordi, El recurso de casación, Legal Publishing, Santiago, 2010.

NúÑEZ, D.; ARRedondo, V.; CARrasco, C.; Guerra, C., "Significados asociados a la participación en juicios orales en niños y niñas víctimas de delitos sexuales”, Revista Praxis, 2015, vo1. 17, № 27.

OlEA, R.; NeIRA, E.; SANHUEZA, F., "Anomalías en el desarrollo del lenguaje”, Revista Chilena de Pediatría, 1958, Vol. 29, № 2.

PARKES, Aisling, Children and international human rights law, the right of the child to be heard, Routledge, New York, 2013.

POSNER, Richard, Reflections on judging, Harvard University Press, Cambridge, 2013. 
RAVETLlat, Isaac; PinOCHET, Ruperto, "El interés superior del niño en el marco de la convención internacional sobre los derechos del niño y su configuración en el derecho civil chileno", Revista Chilena de Derecho, 2015, Vol. 42 , N 3, pp. 903-934.

SÁNCHEZ-EZNARRIAGA, Zarraluqui, "El menor en los procesos de familia”, en Alcón Yustas M. F.; Jääskeläinen F. (eds.), Los menores en el proceso judicial, Tecnos, Madrid, 2011.

SCHAUER, Frederich, Playing by the rules, Oxford Clarendon Law Series, Reino Unido, 1991. 2005.

TARUfFo, Michelle, El vértice ambiguo, Editorial Palestra, Lima,

TAVOLARI, Raúl, El recurso de casación y queja, Editorial Cono Sur, Santiago, 1996.

VARgAS, Macarena; CoRREA, Paula, "La voz de los niños en la justicia de familia en chile”, Revista Ius et Praxis, 2011, Vol. 17, N 1.

VIO, C.; BARRERA, M.; LAZO, B.; QuiROZ, P.; TAPIA, F., "Niveles de ansiedad en niños victimizados: aportes de un programa de preparación", Revista de Psicología, 2011, Vol. 20, № 2.

\section{Jurisprudencia citada}

Corte de Apelaciones de Valdivia, 14 de mayo de 2009 (medida de protección), www.pjud.cl.

Corte de Apelaciones de San Miguel, 7 de diciembre de 2011(cuidado personal), www.pjud.cl.

Corte de Apelaciones de Valparaíso, 18 de julio de 2012 (relación directa y regular), www.pjud.cl.

Corte Suprema, 18 de agosto de 2015 (acción de filiación), www.pjud.cl.

Corte de Apelaciones de Santiago, 22 de noviembre de 2016 (relación directa y regular), www.pjud.cl.

Corte de Apelaciones de Valdivia, 17 de octubre de 2016 (cuidado personal), www.pjud.cl.

Corte de Apelaciones de Santiago, 1 de julio de 2016 (medida de protección), www.pjud.cl.

Corte de Apelaciones de Santiago, 11 de abril de 2016 (relación directa y regular), www.pjud.cl.

Corte de Apelaciones de Punta Arenas, 7 de julio de 2011 (medida de protección), www.pjud.cl. 
3. Normativa citada

Acta $N^{\circ}$ 237-2014, Auto Acordado que regula la implementación de las salas Gesell, 30 de diciembre de 2014.

Acta $N^{\circ}$ 71-2016, Auto Acordado que regula el funcionamiento de tribunales que tramitan electrónicamente.

Código Orgánico de Tribunales chileno. Diario Oficial, 15 de julio de 1943.

Código de Procedimiento Civil chileno. Diario Oficial, 30 de agosto de 1902.

Código Civil chileno.

Constitución Política de la República de Chile de 1980.

Decreto Supremo $N^{\circ}$ 830, Convención sobre los derechos del niño, 27 de septiembre de 1990.

Ley $\mathrm{N}^{\mathrm{o}}$ 19.968, sobre tribunales de familia. Diario Oficial, 30 de agosto de 2014.

Ley $N^{\circ} 19.947$, sobre matrimonio civil. Diario Oficial, 17 de mayo de 2004. 